\title{
Original
}

\section{Regeneration after Two Types of Rat Acute Pancreatitis Compared with Human Autoimmune Pancreatitis}

\author{
Takahisa Yamazaki ${ }^{1)}$, Hitoshi Yoshida ${ }^{1) *}$, Tadashi Honma ${ }^{1)}$, \\ Akitoshi IKEGAMI ${ }^{1}$, Junichi NirkawA ${ }^{1)}$, Shigeki TANAKA ${ }^{1)}$, \\ Toshinari Awal ${ }^{1)}$, Akihiro YUKawA ${ }^{1)}$, Katsuya KITAMURA ${ }^{1)}$, \\ Katsuhiro HanawA ${ }^{1)}$, Tsunao IMAMURA $^{2)}$ and Michio IMAWARI ${ }^{1)}$
}

\begin{abstract}
Complications such as malnutrition and diabetes often result from dysfunctional pancreatic endocrine and exocrine systems in pancreatitis. These systems also differ functionally during healing following pancreatitis. This study examined pancreatic regeneration in both patients with autoimmune pancreatitis (AIP) during treatment with prednisolone, and in two different rat models of acute pancreatitis. Human pancreatic tissue from AIP patients was immunostained to identify pancreatic cells in the phase of regeneration by using an anti-Ki-67 (a proliferation marker) antibody. One rat model used caerulein (CAE) to generate acute edematous pancreatitis (AEP), and the second involved administration of DL-ethionine to generate acute necrotizing pancreatitis (ANP). A labeling index (LI) was established as the ratio of proliferating cell nuclear antigen (PCNA) -labeled acinar cells to total acinar cells, while the ratio of acinar cells showing mitosis to the total number of acinar cells was calculated as the mitotic index (MI). Pancreatic progenitor cells were identified using an anti-pancreatic/duodenal homeobox-1 (PDX-1; an transcription activator) antibody. Additionally, anti-hairy/enhancer-of-split homologue-1 (HES-1) antibody was used to detect immature pancreatic exocrine cells. Human pancreatic tissue with AIP was immunostained. Ki-67-positive cells coincided with acinar cells and ductal cells, and PDX-1-positive cells coincided with pancreatic ductal-type cells. Some $\alpha$-amylase-positive cells and most insulin- and glucagon-positive cells were PDX-1-positive. The severity of AEP was evident $4-12 \mathrm{~h}$ after initial injection of CAE in the first rat model. The PCNA-LI gradually increased to a maximum at $120 \mathrm{~h}$, while the MI peaked at $96 \mathrm{~h}$. In rats with ANP, necrosis and inflammation were prominent but diminished during healing, while the PCNA-LI increased to a peak at 12 days after initial injection of ET, and the MI maximum occurred at 10 days. PDX1 was strongly expressed only in islet cells after AEP, while expression following ANP was intense in islet cells, several ductal-type cells, and a few acinar cells. Few HES-1-positive cells were observed among acinar or ductal cells. This study clarified the temporal nature of pancreatic regeneration in two rat models of acute pancreatitis. The results indicated that regeneration after AEP
\end{abstract}

\footnotetext{
1) Department of Gastroenterology, Showa University School of Medicine, 1-5-8 Hatanodai, Shinagawa-ku, Tokyo 142-8666, Japan.

2) Department of Gastroenterology, Toranomon Hospital.
} 
in rats might not involve pancreatic progenitor cells. However, regeneration after ANP in rats and AIP in humans involves pancreatic progenitor cells that probably derive from the dedifferentiation of acinar and ductal cells affected by inflammation.

Key words : acute pancreatitis, autoimmune pancreatitis (AIP), pancreatic progenitor cells, rat, regeneration

\section{Introduction}

Pancreatitis damages both the endocrine and exocrine function of the pancreas, leading to malnutrition from disrupted digestion and absorption, diabetes, and other complications. These effects worsen with the severity of inflammation and the pancreatic endocrine and exocrine dysfunction differs with the type of pancreatitis, which in turn affects healing.

The present study used two rat models of acute pancreatitis: acute edematous pancreatitis (AEP) and acute necrotizing pancreatitis (ANP). The time course of severity progression and subsequent regeneration was studied for each type of pancreatitis, and differences in the regenerative mechanisms were investigated. Furthermore, the role of pancreatic progenitor cells in regeneration was examined by comparing pancreatic tissues from patients with autoimmune pancreatitis (AIP) ${ }^{1)}$ during treatment with prednisolone (PSL).

The pancreatic/duodenal homeobox-1 (PDX-1) transcription factor is involved in pancreatic differentiation, and is a marker of pancreatic progenitor cells ${ }^{2,3)}$. The emergence of PDX1-positive cells was observed previously during recovery following pancreatitis ${ }^{4,5)}$. The transcription factor neurogenin 3 induces pancreatic progenitor cells to become islet progenitor cells $^{2)}$. In turn, activation of the Notch signaling pathway receptor by ligands such as Delta inhibits neurogenin 3 by activating the hairy/enhancer-of-split homologue 1 (HES-1) transcription inhibitor factor ${ }^{6,7)}$, which can differentiate progenitor cells into pancreatic exocrine cells (Fig. 1).

This study sought to elucidate whether PDX-1-positive cells (progenitor cells) are associated with pancreatic regeneration following different types of pancreatitis (human AIP, rat AEP, or rat ANP). In addition, the role of HES-1 in pancreatic exocrine regeneration was investigated.

\section{Materials and Methods}

\section{Materials}

Human pancreatic tissue was obtained by needle biopsy from patients with AIP admitted to our hospital, and stored until use. Patients were diagnosed according to the Japanese clinical diagnostic criteria for AIP revised and proposed in $2006^{1,8)}$. Forty-nine male Sprague-Dawley (SD) rats and thirty-three male Wistar rats were obtained from Saitama Experimental Animal Supply (Suginomachi, Saitama, Japan). Chemicals were purchased as follows: anti-Ki-67 antibody from DAKO (Produktionsvej, Glostrup, Denmark) ${ }^{\text {) }}$; polyclonal rabbit anti- $\alpha$-amylase antibody and caerulein (CAE) were from Sigma (St. Louis, MO); DL-ethionine (ET) from Wako Pure Chemicals (Doshoumachi, Osaka, Japan); mouse monoclonal anti-insulin antibody and polyclonal rabbit anti-glucagon antibody from Zymed Laboratories (South San Francisco, CA); mouse monoclonal anti-proliferating cell nuclear antigen 


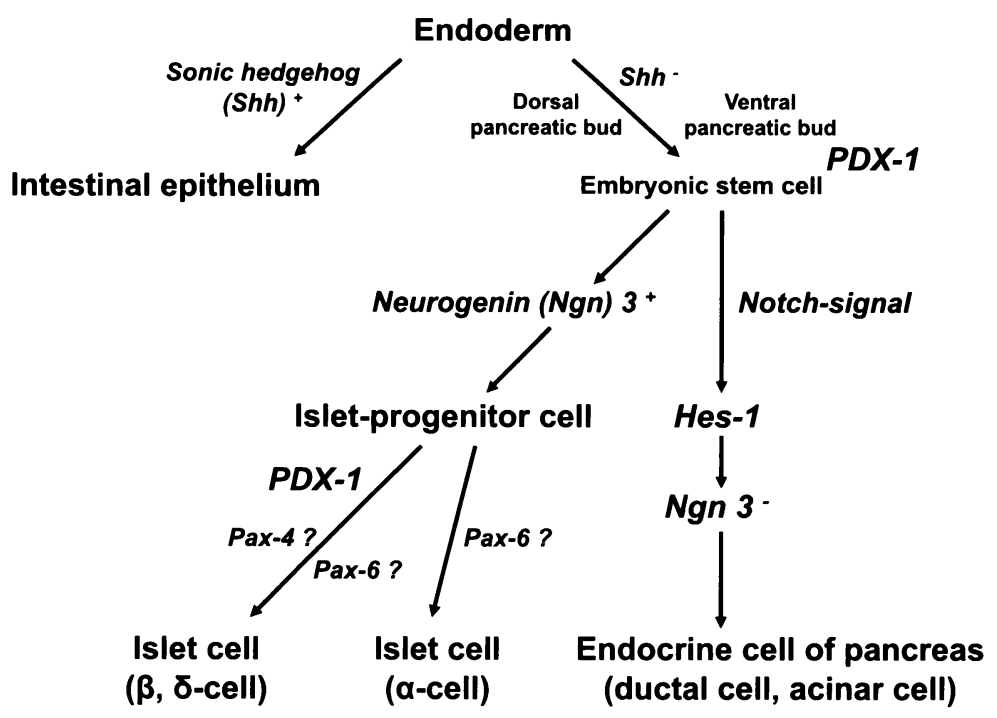

Fig. 1. Development and differentiation of pancreas (hypothesis) PDX-1: pancreatic/duodenal homeobox-1

(PCNA) antibody ${ }^{10,11)}$ from BD Biosciences Pharmingen (Akasaka, Tokyo, Japan); blue starch polymer for amylase (Neo Amylase Test) from Daiichi Pure Chemicals (Nihonbashi, Tokyo, Japan). The following antibodies were kindly provided: anti-PDX-1 antibody ${ }^{4,5)}$ from Dr. Yoshitaka Kajimoto and Dr. Hideaki Kaneto (First Department of Internal Medicine, Osaka University, Osaka, Japan); anti-HES-1 antibody ${ }^{6,7,12)}$ from Dr. Tetsuo Sudo (Toray Pharmaceutical Laboratory, Kamakura, Japan).

Human pancreatic tissue from AIP patients

Human pancreatic tissue from AIP patients was immunostained before and during PSL treatment ${ }^{13,14)}$ to identify pancreatic progenitor cells or embryonic stem cells, using a proliferation marker, Ki-67, and a transcription activator, PDX-1, during the healing phase of AIP. Pancreatic endocrine and exocrine cells were also localized using antibodies against insulin, glucagon, and $\alpha$-amylase. The histological study of pancreatic tissue obtained by needle biopsy was approved by the Ethics Committee of Showa University School of Medicine and was performed with informed patient consent.

\section{Acute pancreatitis in rats}

Male SD rats weighing 170-200 $\mathrm{g}$ were sacrificed by exsanguination at 4, 6, 12, 24, 48, 72, $96,120,144,168$, and $336 \mathrm{~h}$ following an initial administration of four intraperitoneal (ip) injections of CAE $(20 \mu \mathrm{g} / \mathrm{kg}$ body weight $)$ dissolved in physiological saline (PS) to induce $\mathrm{AEP}^{15,16)}$ (Fig. 2). Control rats were given four ip injections of PS without CAE.

Male Wistar rats weighing approximately $170 \mathrm{~g}$ were fed a protein-deficient diet for 11 days in total and given an ip administration of $200 \mathrm{mg} / \mathrm{kg}$ of body weight of ET dissolved in PS every $24 \mathrm{~h}$ for the last four days to induce ANP. Animals were sacrificed by exsanguination $4,6,8,10,12,14,16,18,20$, and 22 days later after an initial ip ${ }^{16-18)}$ (Fig. 2). Control rats were given four ip injections of PS without ET. 


\section{Caerulein-induced pancreatitis (acute edematous pancreatitis: AEP)}

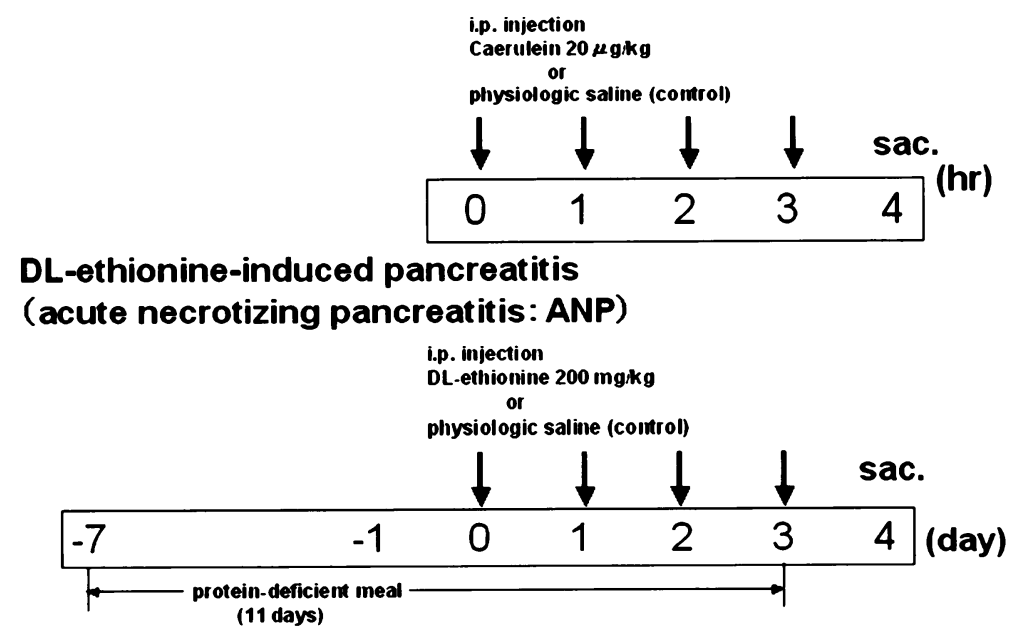

Fig. 2. Experimental protocols for inducing pancreatitis in rats ip: intraperitoneal, sac: time of sacrifice; $h$ : hours

The pancreas was removed immediately from all rats following sacrifice and weighed while wet. The Committee for Animal Experimentation of Showa University approved all animal protocols used in this study.

\section{Histological examination}

For light microscopic examination, the rat pancreatic tissue was fixed in $10 \%$ formaldehyde, embedded in paraffin wax, and stained with hematoxylin-eosin (H-E).

\section{Immunohistochemical staining}

Rat pancreas for immunostaining was fixed in $4 \%$ paraformaldehyde, snap frozen, and then sectioned at $-20^{\circ} \mathrm{C}$. Sections were thawed in a microwave and rinsed in running water, before incubating for $20 \mathrm{~min}$ in $0.3 \% \mathrm{H}_{2} \mathrm{O}_{2} /$ methanol to block endogenous peroxidase activity and reduce background staining. The tissue was then incubated with anti-PCNA antibody, anti-PDX-1 antibody, or negative control for $1 \mathrm{~h}$. The biotinylated secondary antibodies for anti-PCNA, and anti-PDX-1 antibodies were added and incubated for 15, and $30 \mathrm{~min}$ respectively, before the substrates reaction for 15 , and $30 \mathrm{~min}$, respectively. Samples were rinsed in running water after color was developed using $0.02 \%$ diaminobenzidine (DAB) in buffer. Nuclei were stained with hematoxylin. Samples were then dehydrated with $70-100 \%$ ethanol, penetrated with xylene, and sealed. All reactions were carried out at room temperature.

Immunohistochemistry for HES-1 was performed according to the method modified by Dr. Ryoichiro Kageyama and provided by Dr. Itaru Imayoshi (Institute for Virus Research, Kyoto University, Kyoto, Japan ${ }^{12}{ }^{12}$. The pancreas was fixed in $4 \%$ periodate-lysineparaformaldehyde (PLP), mounted with OCT compound, and sectioned frozen. The sections were incubated in $10 \mathrm{mM}$ citric buffer for $5 \mathrm{~min}$, and then reacted with anti-HES-1 antibody 
or negative control for $1 \mathrm{~h}$. A solution $\left(0.3 \% \mathrm{H}_{2} \mathrm{O}_{2}\right.$ in methanol) that blocks endogenous peroxidase and reduces background staining was allowed to react for $30 \mathrm{~min}$ before adding it to the tissue. The biotinylated secondary antibody was added and incubated for $1 \mathrm{~h}$, and then the enzyme substrate was reacted for $1 \mathrm{~h}$. The subsequent steps were carried out as described for the other sections.

\section{Severity of rat acute pancreatitis}

Severity of AEP was assessed according to serum amylase levels and wet weight of pancreatic tissue as indicators, whereas severity of ANP was evaluated histologically according to inflammatory cell infiltration and acinar cell necrosis.

\section{Mitotic index and labeling index during pancreatitis}

We stained pancreas specimens by using hematoxylin-eosin (H-E) and an anti-PCNA antibody. We used mitotic index (MI) and labeling index ( $\mathrm{LI}$ ) to evaluate regeneration in each case of pancreatitis. MI is the number of acinar cells in mitosis/total number of acinar cells. LI is the number of PCNA-positive acinar cells/total number of acinar cells.

\section{Serum amylase activity}

Blood samples were centrifuged at $3,000 \mathrm{rpm}$ for $10 \mathrm{~min}$ at $4{ }^{\circ} \mathrm{C}$ to obtain rat sera. Serum amylase levels were measured using blue starch polymer.

\section{Statistical Analysis}

Statistical analysis was performed using Mann-Whitney's U-test for comparison of means. $P$ values less than 0.05 were considered statistically significant.

\section{Results}

Various markers for human AIP were localized by immunostaining in the human patient samples. Ki-67-positive cells coincided with acinar cells and ductal cells (Fig. 3-1, 3-2), and PDX-1-positive cells coincided with pancreatic ductal-type cells (Fig. 4). Some $\alpha$-amylasepositive cells (data; not shown) and most insulin- and glucagon-positive cells were also PDX-1-positive (Fig. 5).

\section{Body weight of rats with pancreatitis}

There were no differences in the body weights between the AEP rats and controls (Fig. 6). In contrast, the ANP rats differed significantly in body weight compared to controls until day 18 after the injection of ET. The weight of ANP rats decreased until day 6 after injection and then increased (Fig. 7).

\section{Pancreatic tissue in rats with pancreatitis}

Edema and vacuole formation was prominent in tissues from AEP rats $6 \mathrm{~h}$ after the injection of CAE. Such signs of inflammation diminished over time, and nuclear mitosis was observed in the acinar cells of AEP tissues $96 \mathrm{~h}$ after injection (Fig. 8). The ANP rats showed severe necrosis and fibrosis at day 6 after the ET injection, while nuclear mitosis of acinar cells was not prominent in ANP tissues until 10 days post-injection (Fig. 9). 


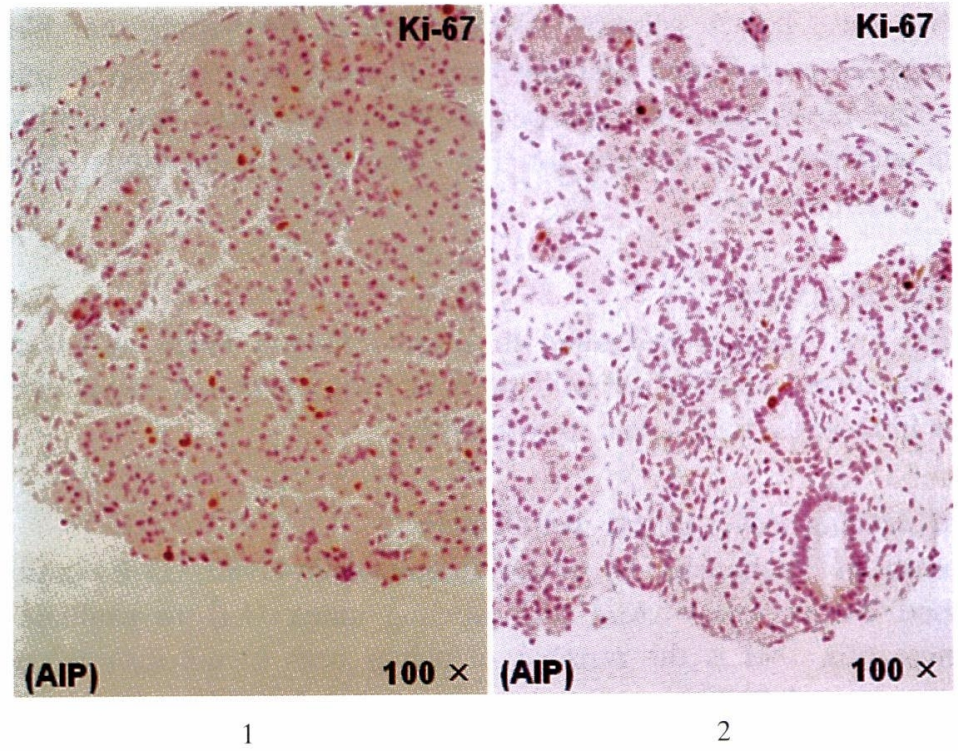

Fig. 3. Ki-67-positive cells in human autoimmune pancreatitis (AIP) during treatment with prednisolone (PSL)

Ki-67-positive cells coincide with acinar cell and ductal cells in human AIP.

1: Ki-67-positive acinar cells. Ki-67-labeling index of pancreatic acinar cells (Ki-67-positive acinar cells/total acinar cells) $=2.69 \pm 0.48 \%$.

2: Ki-67-positive ductal cells. Ki-67-labeling index of pancreatic ductal cells (Ki-67-positive ductal cells/total ductal cells) $=4.03 \pm 1.13 \%$.

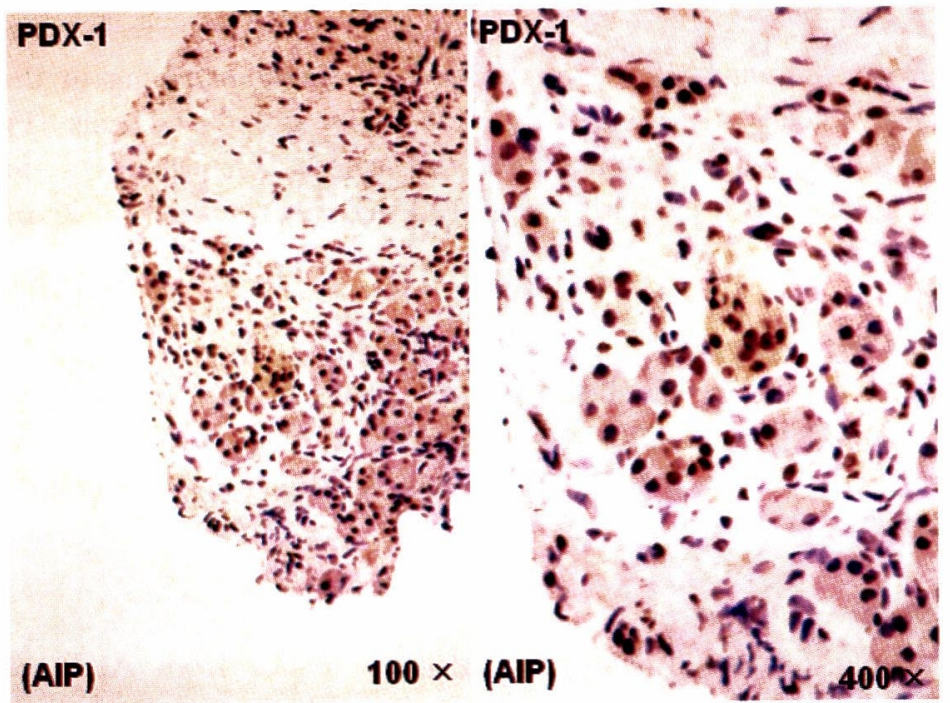

Fig. 4. PDX-1-positive cells in human AIP during treatment with PSL

PDX-1-positive cells coincide with pancreatic ductal-type cells in human AIP. 


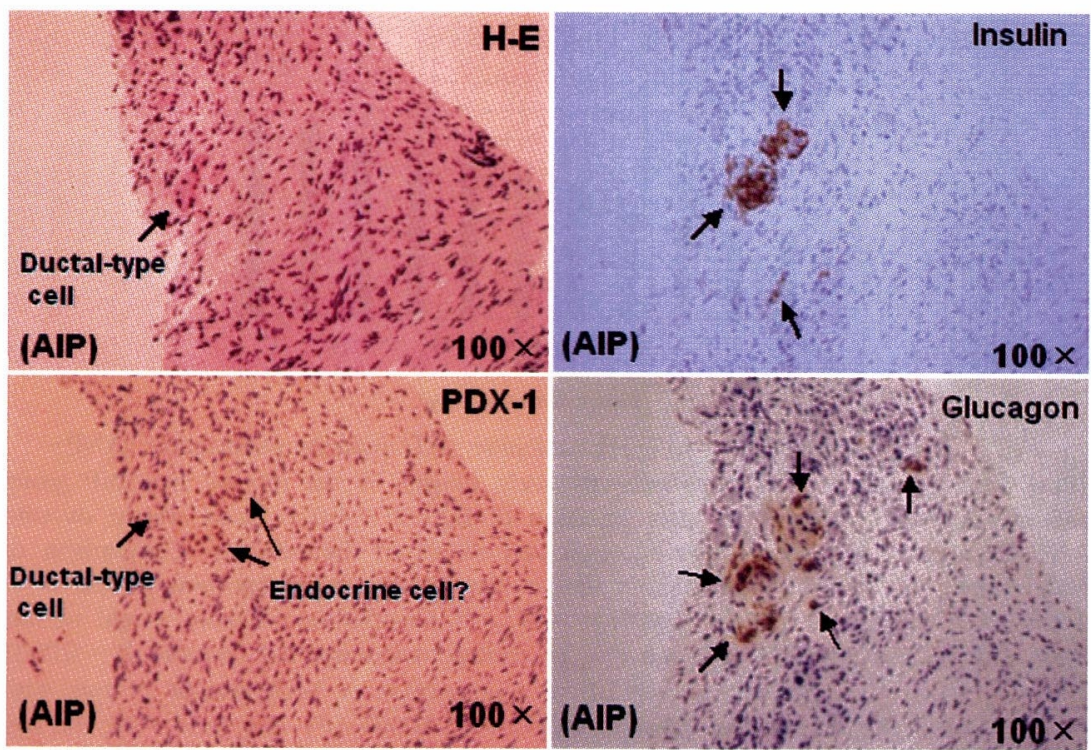

Fig. 5. PDX-1, insulin-, and glucagon-positive cells in human AIP during treatment with PSL

The ductal-type cells (arrows) seemed to be PDX-1-positive. Most of insulin- or glucagon-positive cells (arrows) were PDX-1-positive.

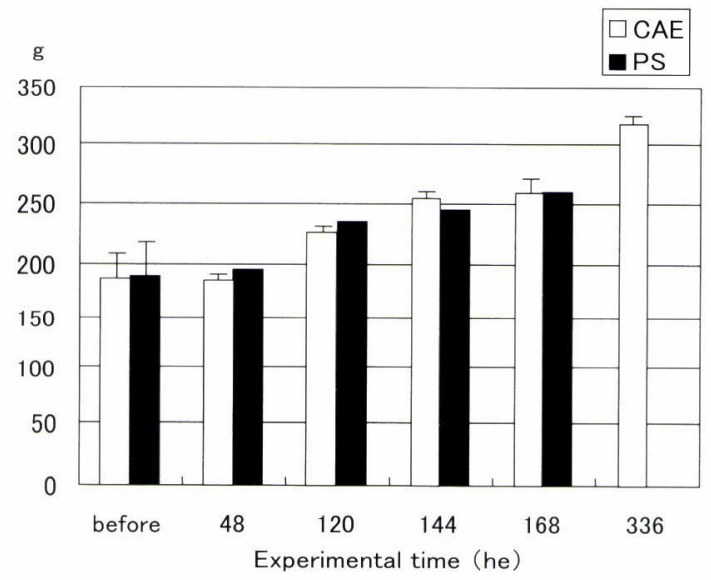

Fig. 6. Body weight of rats with caerulein (CAE) -induced pancreatitis (AEP)

There were no differences between body weights of AEP rats and no AEP (control) rats.

Wet weights of pancreas in rats with pancreatitis

The mean wet weight of pancreas from the AEP rats increased to a maximum at 6-12 h after the CAE injection. Thereafter, the pancreatic tissue weight decreased in AEP rats to be slightly less than control rats, in parallel with the diminished edema and vacuolization (Fig. 8, 10). Wet weights of pancreas from ANP rats decreased until day 6 after the ET 


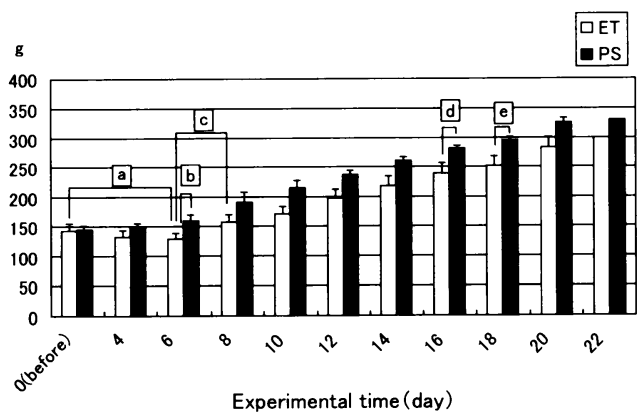

Fig. 7. Body weight of rats with DL-ethionine (ET)-induced pancreatitis (ANP) There were significant differences between body weights of the rats in the ANP group and the controls until day 18 after injection of ET $(P<0.05)$. Body weight of with ANP decreased until day 6 post-injection and increased thereafter. a. Comparison of body weight of rats with ANP before and at day 6 after initial injection of ET. $P=$ 0.0004 (ET day $0: n=21$; ET day $6: n=19$ ). b. Comparison of body weight of rats with ANP 6 days after ET injection and physiologic saline-injected controls. $P=0.0001$ (ET day $6: \mathrm{n}=19$; PS day $6: \mathrm{n}=10$ ). c. Comparison of body weight of rats with ANP at day 6 and day 8 after injection of ET. $P<0.0001$ (ET day $6: n=19$; ET day $8: n=17)$. d. Comparison of body weight of rats with ANP at day 16 after injection of ET and saline-injected controls. $P=0.0006$ (ET day 16: $n=7 ;$ PS day 16: $n=4$ ). e. Comparison of body weight of rats with ANP at day 18 after ET injection and salineinjected controls. $P=0.0357$ (ET day $18: \mathrm{n}=5$; PS day $18: \mathrm{n}=3$ ).

injection, and then gradually increased; ANP values were less than controls during this time course (Fig. 11).

\section{Serum amylase levels in rats with $A E P$}

Serum amylase levels were higher in AEP rats than in controls until $12 \mathrm{~h}$ post-injection. The maximum serum amylase levels were seen at $6 \mathrm{~h}$, after which the levels gradually decreased (Fig. 12).

\section{Mitotic index of acinar cells in rats with pancreatitis}

We investigated the regeneration of impaired pancreas with two histological indicators after each type of acute pancreatitis to reveal an indication of nuclear mitosis or MI. AEP rat pancreas showed a significantly increased MI compared with control pancreas, with the maximum MI observed $96 \mathrm{~h}$ post-injection (Fig. 13). The MI in ANP rat pancreas also increased significantly compared with controls, with the maximum observed at day 10 postinjection (Fig. 14).

\section{Labeling index in pancreas of rats with pancreatitis}

We calculated an index, the LI, for the proportion of PCNA-positive acinar cells in rat pancreas from both groups. PCNA-positive cells were prominent in AEP pancreas from 72 through $144 \mathrm{~h}$ following the injection of CAE (Fig. 15); LI values were significantly increased compared with controls, with the maximum LI observed $120 \mathrm{~h}$ post-injection (Fig. 16). PCNA-positive cells in ANP rats were prominent from day 12 through day 14 following the ET injection (Fig. 17); values were also increased significantly compared to controls 

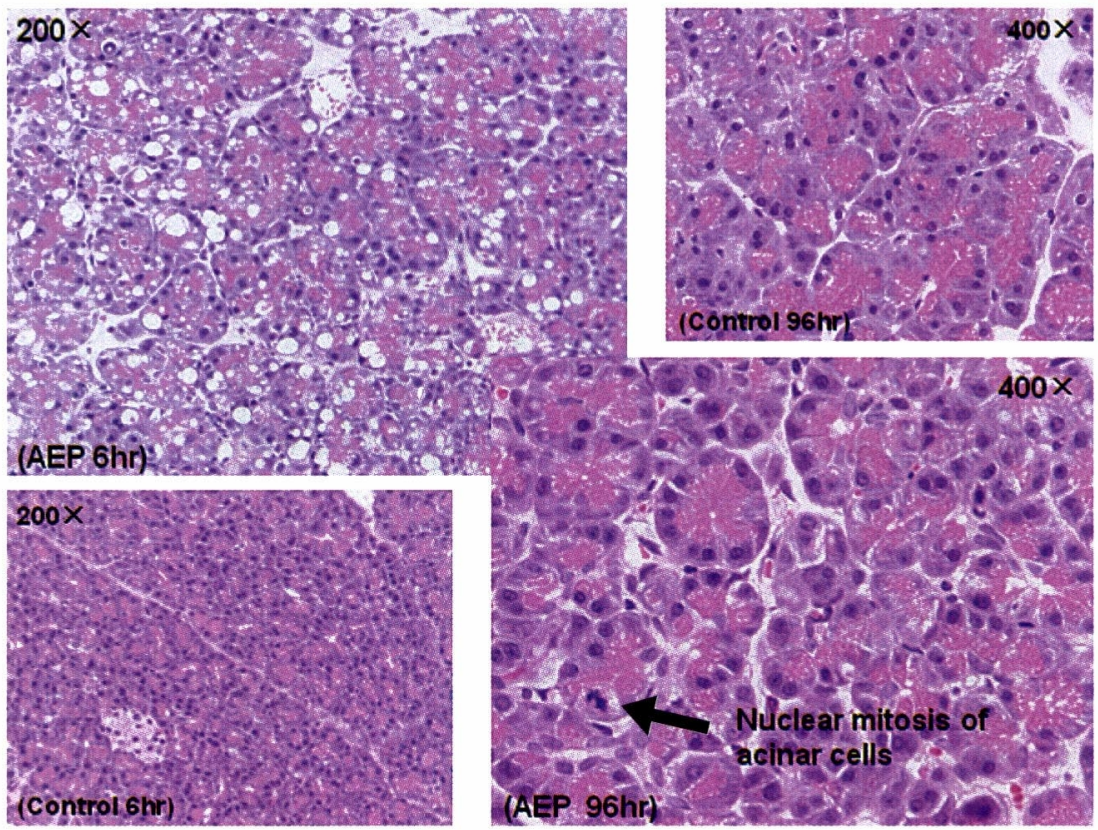

Fig. 8. Pancreatic tissue in rats with AEP (H-E)

Edema and vacuole formation were prominent in AEP rats $6 \mathrm{~h}$ after injection of CAE. These inflammatory signs were diminished and nuclear mitosis of acinar cells (arrow) was observed in AEP rats $96 \mathrm{~h}$ post-injection.

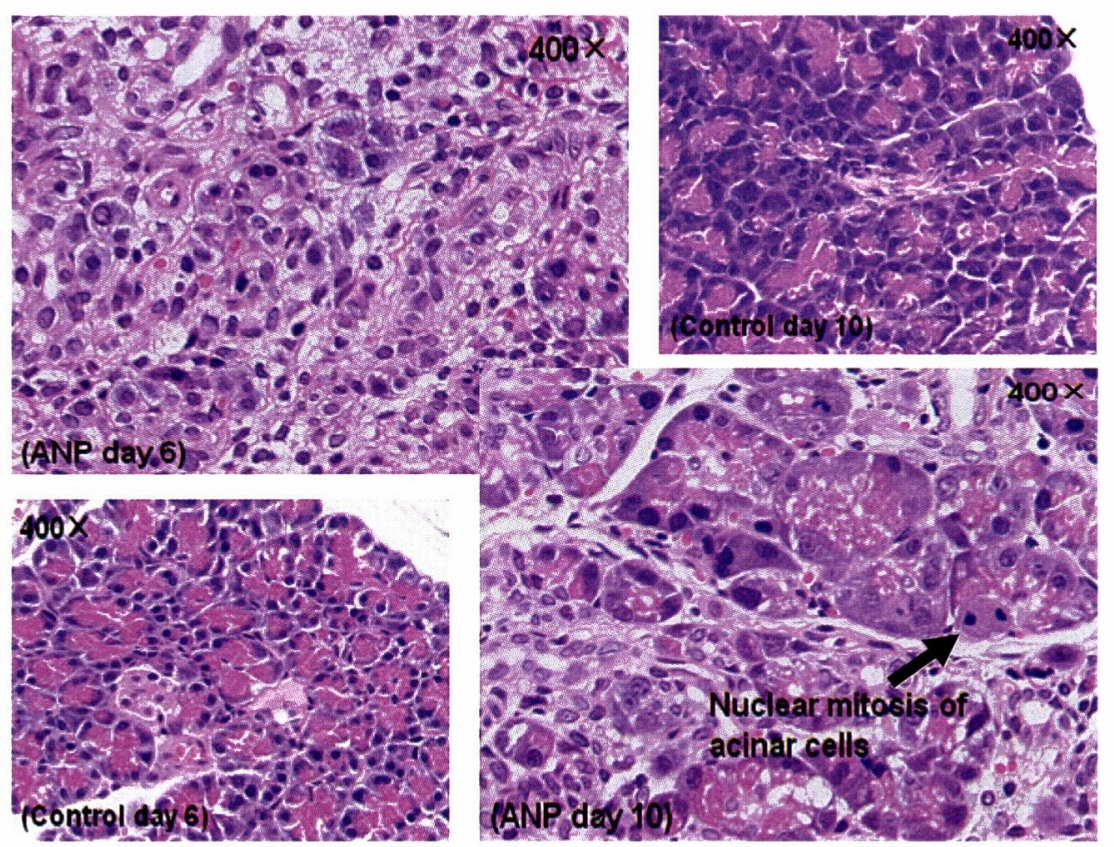

Fig. 9. Histological examination of pancreatic tissue in rats with ANP (H-E) Severe necrosis and fibrosis were observed on day 6 after ET injection. Thereafter, nuclear mitosis of acinar cells (arrow) was prominent in ANP rat pancreas 10 days post-injection. 


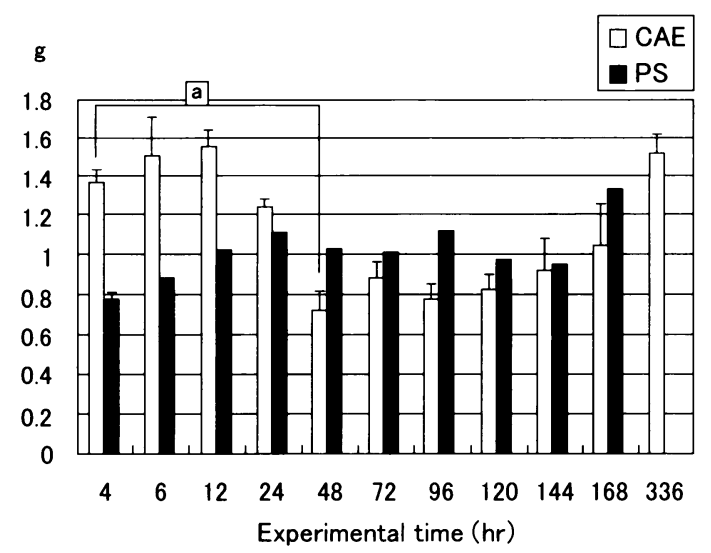

Fig. 10. Wet weight of pancreas in rats with AEP

Wet weight of pancreas in AEP rats increased, with the maximum observed at 6-12 $\mathrm{h}$ after CAE injection. The weight decreased briefly thereafter to less than controls as edema and vacuole formation improved. Comparison of wet weight of pancreas in rats with AEP $4 \mathrm{~h}$ and $48 \mathrm{~h}$ after initial injection of CAE. $P=0.0159$ (CAE $4 \mathrm{~h}: \mathrm{n}=4$; CAE $48 \mathrm{~h}: \mathrm{n}=5$ )

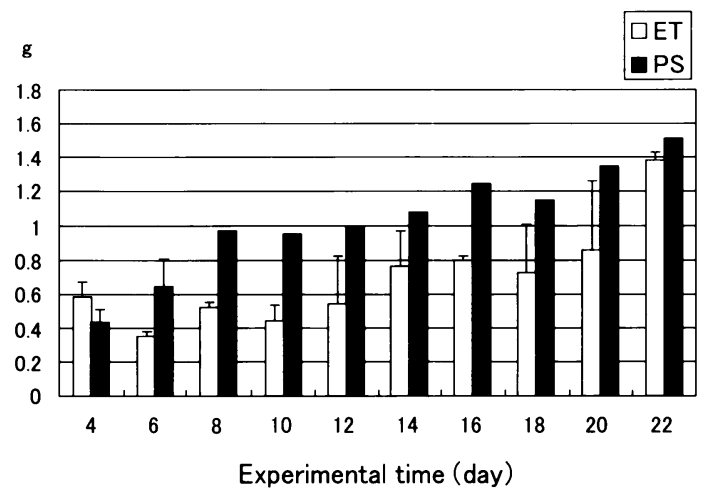

Fig. 11. Wet weight of pancreas from rats with ANP Wet weight of pancreas in ANP rats decreased until day 6 after ET injection, and then gradually increased. In the same period, wet weight of pancreas in ANP rats were less than that in controls.

in these rats, with the maximum value observed 12 days post-injection (Fig. 18).

\section{Labeled acinar cells in pancreas of rats with ANP}

ANP rats showed fewer labeled pancreatic acinar cells than controls until 6 days postinjection, although the difference disappeared by day 8 (Fig. 19).

\section{PDX-1-positive cells in pancreas of rats with pancreatitis}

Pancreatic progenitor cells were identified and localized during regeneration by immunostaining rat pancreas for PDX-1 expression. PDX-1-positive cells were predominant among 


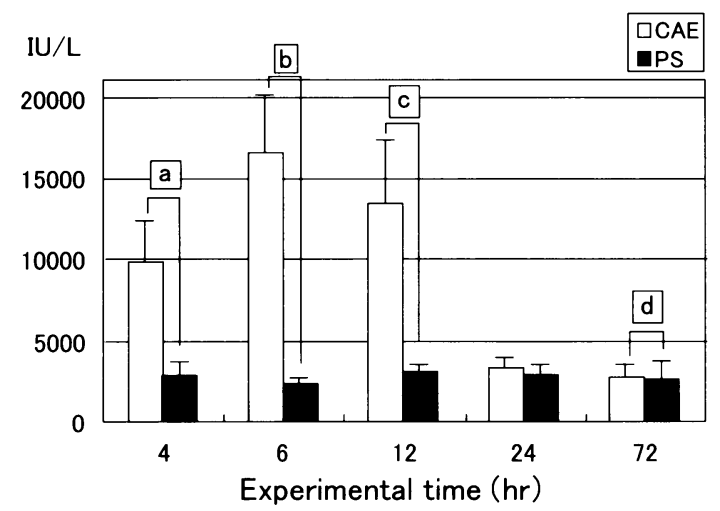

Fig. 12. Serum amylase levels in rats with AEP

Serum amylase levels in AEP rats increased to a maximum at $6 \mathrm{~h}$, and then gradually decreased. a. Comparison of serum amylase levels in AEP rats $4 \mathrm{~h}$ after initial injection of CAE and PS-injected controls. $P<0.0001$ (CAE $4 \mathrm{~h}: \mathrm{n}=10$; PS $4 \mathrm{~h}: \mathrm{n}=$ 8). b. Comparison of serum amylase levels in AEP rats $6 \mathrm{~h}$ after CAE injection and PS-injected controls. $P=0.0040($ CAE $6 \mathrm{~h}: \mathrm{n}=8$; PS $6 \mathrm{~h}: \mathrm{n}=4)$. c. Comparison of serum amylase levels in AEP rats $12 \mathrm{~h}$ post-injection and PS-injected controls. $\mathrm{P}=$ 0.0095 (CAE $12 \mathrm{~h}: \mathrm{n}=6$; PS $12 \mathrm{~h}: \mathrm{n}=4)$ ). d. Comparison of serum amylase levels in AEP $72 \mathrm{~h}$ after CAE injection and PS-injected controls. $P=0.9110(\mathrm{CAE} 72 \mathrm{~h}: \mathrm{n}=20$; PS $72 \mathrm{~h}: \mathrm{n}=5$ ).

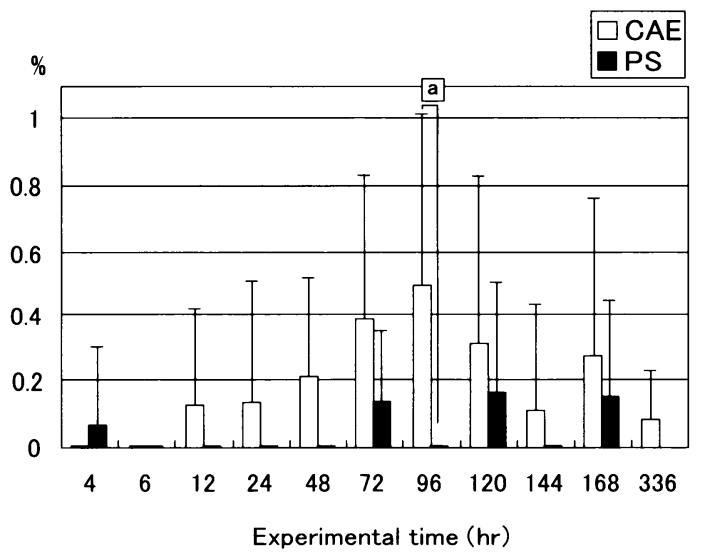

Fig. 13. Mitotic index of acinar cells (MI) in rats with AEP

MI in AEP increased significantly, with maximum MI observed at $96 \mathrm{~h}$. a. Comparison between MI in AEP rats $96 \mathrm{~h}$ post-injection and PS-injected controls. $P=0.0492$ (CAE $96 \mathrm{~h}: \mathrm{n}=25$; PS $96 \mathrm{~h}: \mathrm{n}=5$ ).

islets in the AEP rats, while islet, ductal-type, and acinar cells were PDX-1-positive in ANP rat pancreas (Fig. 20).

HES-1-positive cells in rats with ANP

Immature pancreatic exocrine cells and even specific pancreatic progenitor cells were not identified by immunostaining for HES-1 in the pancreas of ANP rats (Fig. 21). 


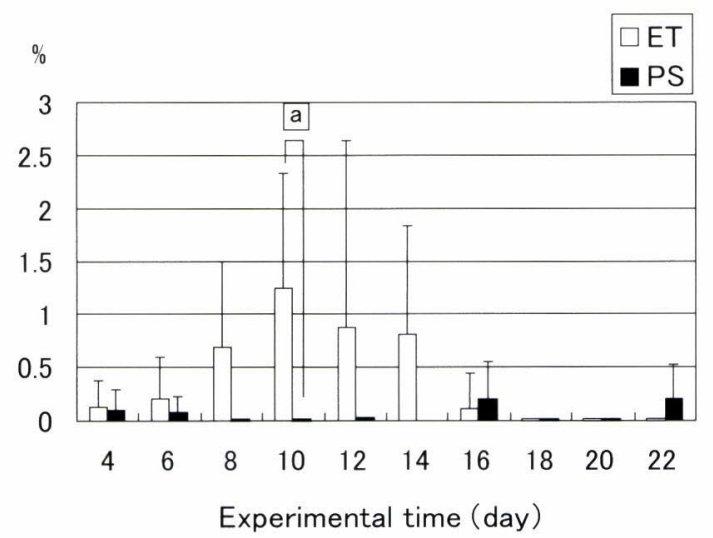

Fig. 14. Mitotic index of acinar cells in pancreas of rats with ANP

MI in ANP rats increased significantly, with maximum MI observed 10 days after injection of ET. a. Comparison between MI in ANP rats and control rats at day 10. $P=$ 0.0054 (ET day 10: $\mathrm{n}=10 ;$ PS day 10: $\mathrm{n}=5$ ).
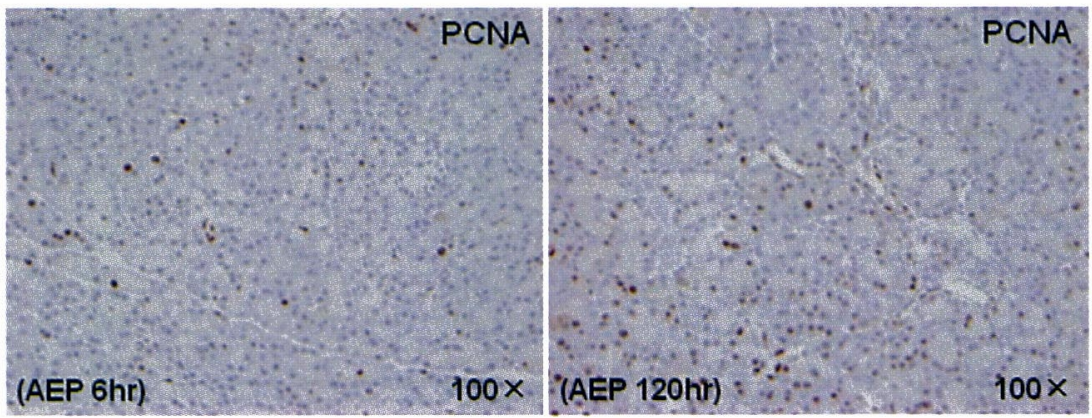

Fig. 15. PCNA-positive cells in pancreas of rats with AEP PCNA-positive cells were prominent $120 \mathrm{~h}$ after injection of CAE.

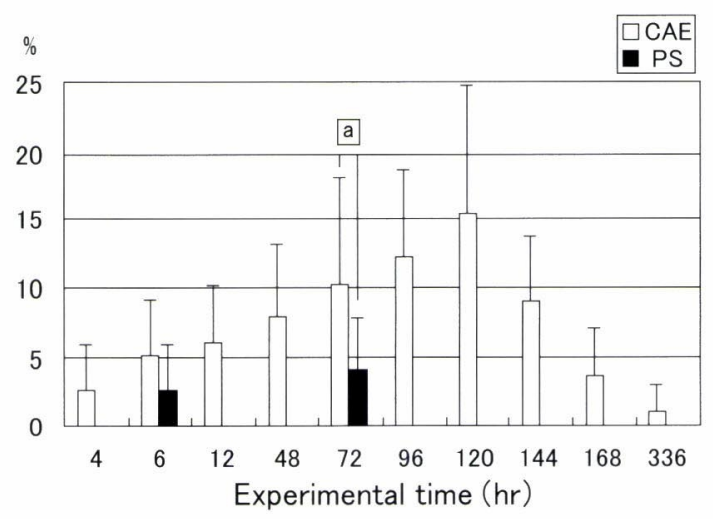

Fig. 16. Labeling index (ratio of PCNA-labeled acinar cells to total acinar cells) in pancreas of rats with AEP

Labeling index (LI) in AEP rats increased significantly compared with controls to maximum at $120 \mathrm{~h}$ after injection of CAE. a. Comparison of LI in AEP rats $72 \mathrm{~h}$ after injection of CAE and that in PS-injected controls. $P=0.0066($ CAE $72 \mathrm{~h}: \mathrm{n}=25 ;$ PS $72 \mathrm{~h}: \mathrm{n}=5)$. 


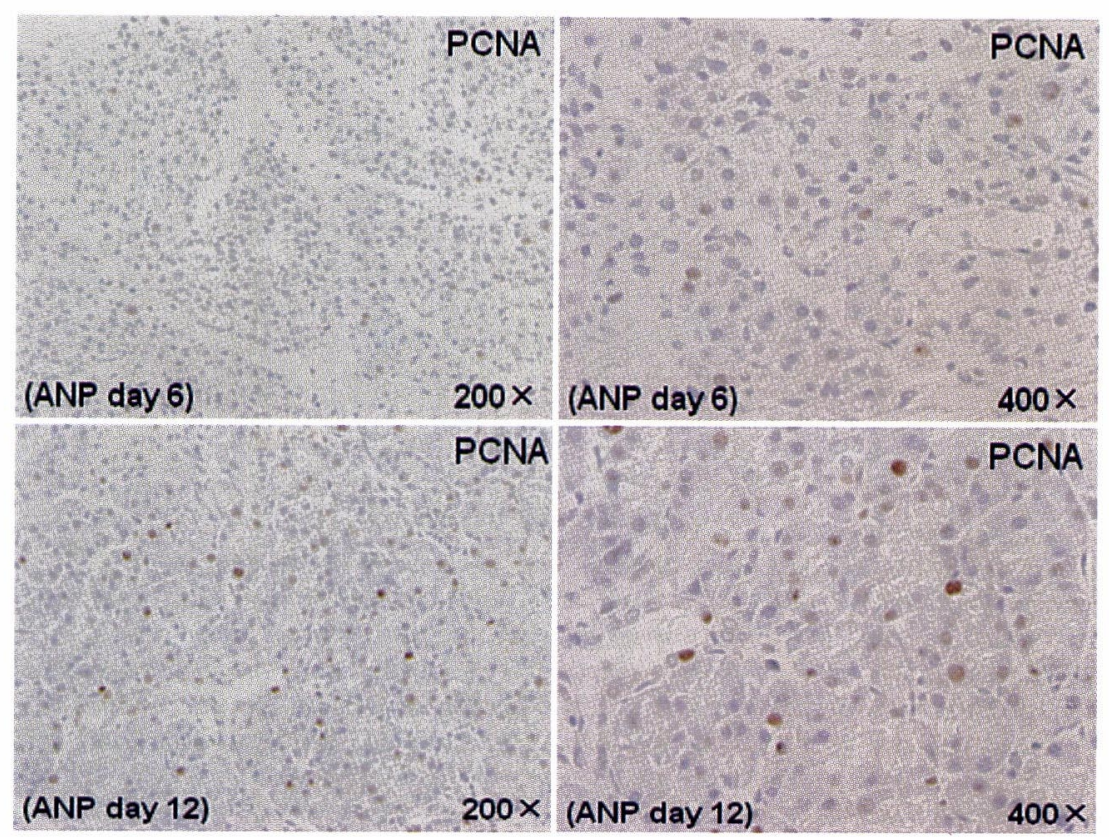

Fig. 17. PCNA-positive cells in pancreas of rats with ANP PCNA-positive cells were prominent 12 days after initial injection of ET.

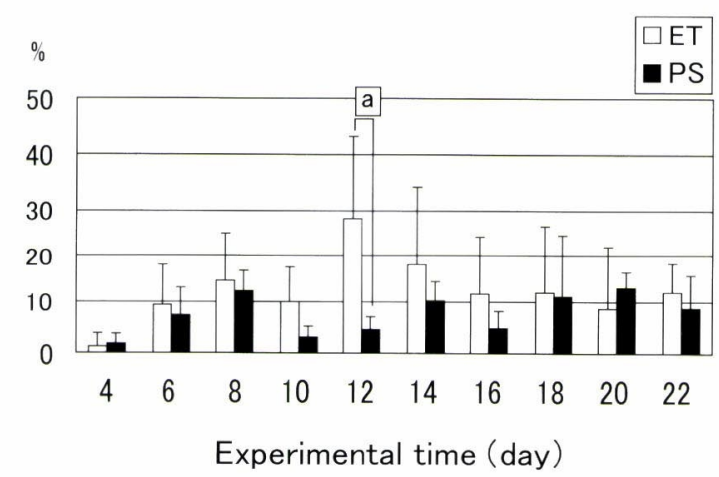

Fig. 18. Labeling index in pancreas of rats with ANP LI in ANP increased significantly compared with controls, with maximum LI observed 12 days after ET injection. a. Comparison of LI in ANP rats 12 days after ET injection and PS-injected controls. $P=0.0013$ (ET day 12: $\mathrm{n}=10$; PS day $12: \mathrm{n}=5$ ).

\section{Discussion}

This study demonstrated proliferating cells in the pancreatic tissues of AIP patients during treatment with PSL, supporting our earlier work suggesting that the emergence of pancreatic acinar cells reveals not only recovery after AIP but also tissue regeneration ${ }^{13,14)}$. Collectively the results of the previous ${ }^{9)}$ and present study suggested that Ki-67-positive cells appearing during regeneration after pancreatitis may be either acinar or ductal cells. 


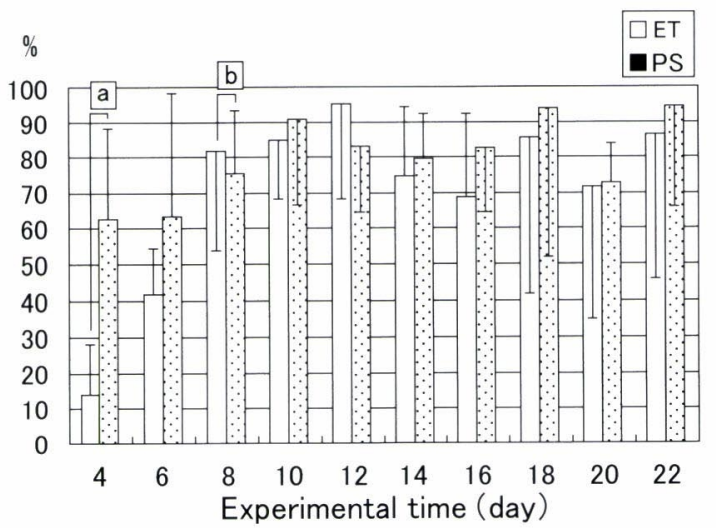

Fig. 19. Labeling index of acinar cells in pancreas of rats with ANP Labeled acinar cells in ANP rats were fewer than in control rats until day 6 after injection of ET. However, there was no difference between labeled acinar cells in ANP rats at day 8 after injection of ET compared to PS-injected controls. a. Comparison of labeled acinar cells in ANP rats 4 days after injection of ET and PS-injected controls. $P$ $=0.0026$ (ET day $4: \mathrm{n}=10$; PS day $4: \mathrm{n}=10$ ) b. Comparison of labeled acinar cells in ANP rats 8 days after injection of ET and PS-injected controls. $P=0.7354$ (ET day $8: \mathrm{n}=15$; PS day $8: \mathrm{n}=5$ ).

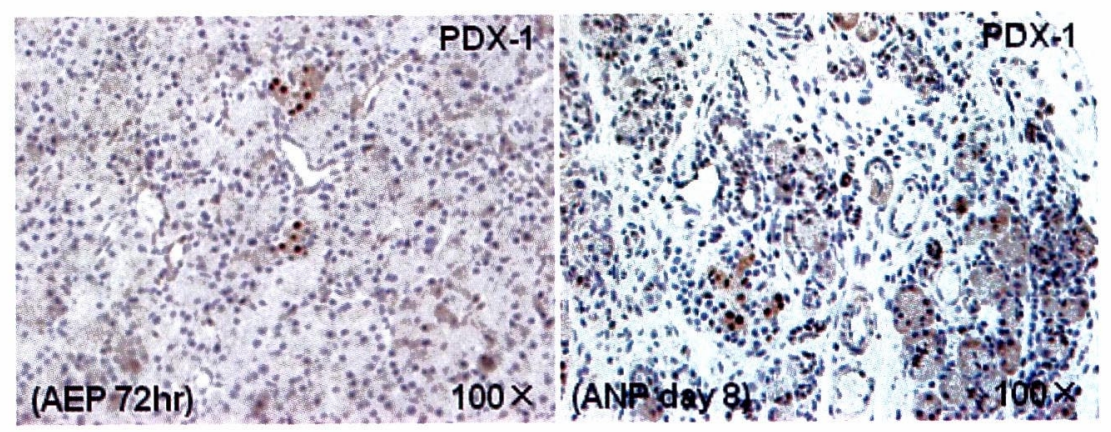

Fig. 20. PDX-1-positive cells in pancreas of rats with pancreatitis PDX-1-positive cells in AEP rats were found predominantly at islets, but those in ANP rats were found at islet cells, ductal-type cells, and acinar cells.

Furthermore, the immunostaining for pancreatic differentiation marker PDX-1 implicated the ductal-type cell ${ }^{4)}$ as a key cell for differentiation during regeneration of pancreatic endocrine or exocrine cells. PDX-1-positive cells coincided with cells positive for $\alpha$-amylase, representing immature exocrine cells, but also with cells stained for insulin and glucagon, which represent immature endocrine cells in the islets. These results suggested that ductal-type cells morphologically resembling ductal cells could be important cells in the regeneration of ductal, acinar, and endocrine cells after AIP.

In studies of mouse pancreas development ${ }^{2)}$, Notch-1 signaling induces HES-1 ${ }^{2)}$, which in turn inhibits the induction of neurogenin 3. Thus, PDX-1-positive cells probably differentiate into pancreatic exocrine cells. A recent immunohistochemical study demonstrated pancreatic regeneration after necrotizing pancreatitis in mice ${ }^{4)}$. They reported that HES-1 and Jag- 


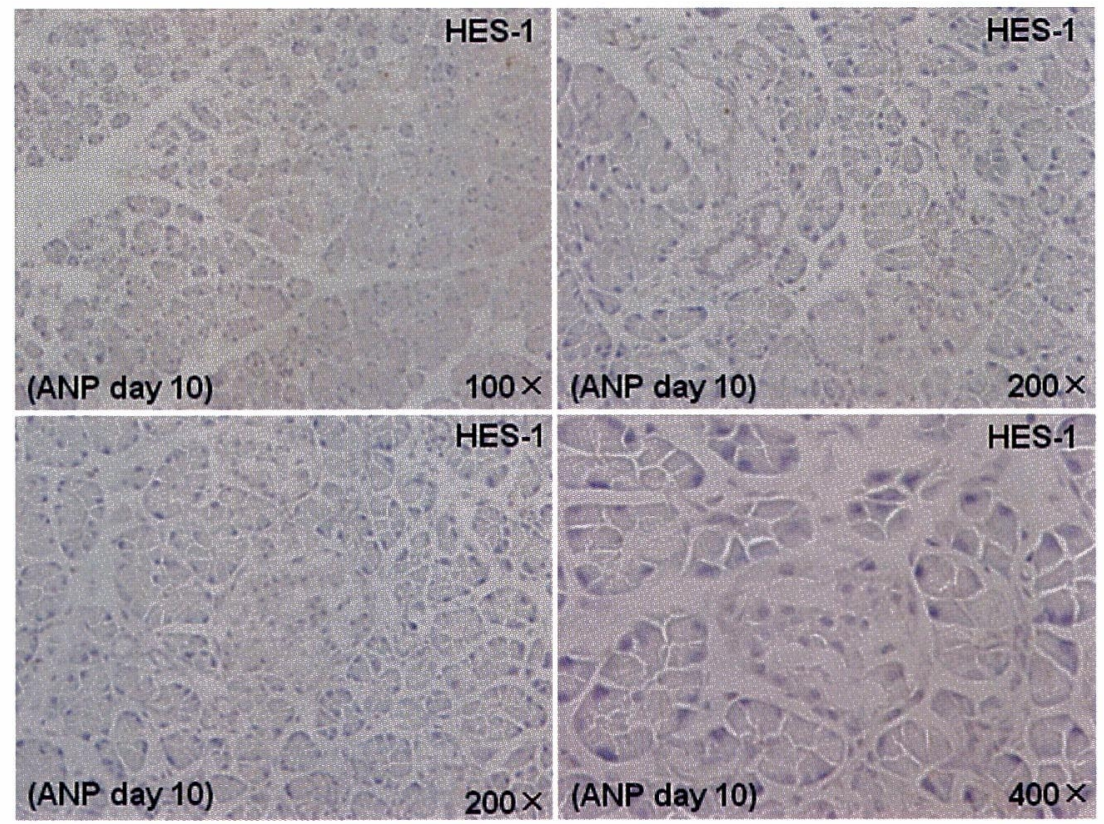

Fig. 21. HES-1-positive cells in pancreas of rats with ANP HES-1 was not expressed in specific cells in pancreas after ANP.

ged 1 are induced by Delta-1 and Notch signaling in regenerating acinar cells, and in turn regeneration is automatically accelerated in acinar cells ${ }^{4)}$. The present study investigated whether pancreatic progenitor cells, namely ductal-type cells in the pancreas, differentiate into the exocrine cells observed in rat models of acute pancreatitis during treatment of human AIP. Because acute pancreatitis varies clinically with etiology, the effects on endocrine and exocrine function may also vary with the cause and severity of the pancreatitis. To clarify whether the regeneration phenomenon is dependent on the type of pancreatitis, this study examined differences in regeneration between two types of rat acute pancreatitis.

Rat body weights in the AEP group was not significantly different from that of control rats. However, induction of ANP resulted in significantly lighter rats compared to controls. In AEP rats, the pancreas increased in weight up to a maximum at $12 \mathrm{~h}$ after the CAE injection, and serum amylase levels increased to a maximum at $6 \mathrm{~h}$. In the same period, the tissue showed severe vacuole formation and interstitial edema. All these signs diminished after that point, with pancreas weight returning to control levels. In contrast, the ANP rats showed an initial decrease in organ weight. The weight was the lowest at day 8 , and remained reduction for a long period thereafter. The ANP pancreatic tissues also showed collapsed acinar cells and fibrosis, with significant destruction of pancreatic structure. Overall, the peak of inflammation was observed at 6-12 h after CAE injection in the AEP rat group, and by day 8 in the ANP rat group. This result is compatible with our previous reports ${ }^{15-18)}$.

The AEP rats showed maximal nuclear mitosis at $96 \mathrm{~h}$ after CAE injection, while the acinar cells were maximally PCNA-labeled $120 \mathrm{~h}$ post-injection. In the ANP rat group, the MI of acinar cells peaked on day 10, and the PCNA-LI was highest on day 12 . This 
indicated the peak of acinar cell regeneration in the AEP group to be at $96-120 \mathrm{~h}$ after induction of the pancreatitis, and 10-12 days in ANP rats. There was a small difference between the period of maximum MI and that of the maximum PCNA-LI. Such time lags during regeneration may reflect differences in severity or cause of pancreatitis, or that the maximum regenerative activity could occur between the peaks of MI and PCNA-LI.

The evaluation of acinar cell regeneration after pancreatitis revealed a low PCNA-LI in the early phase of ANP. The number of acinar cells might have decreased due to necrosis or collapse, and fibroblast migration or proliferation might increase transiently in the early phase of ANP compared to those activities in acinar cells. Regeneration of acinar cells increased after the early phase, indicating different regenerative activities among pancreatic cells following pancreatitis. A striking difference was between types of PDX-1-positive cells in periods of greatest regenerative activity. While PDX-1 was predominantly expressed in islet cells during AEP recovery, islet cells, ductal-type cells ${ }^{4)}$, and acinar cells showed PDX1 staining after ANP. As previously described, AEP and ANP have different causes and clinical conditions, prompting speculation about similar differences in the regenerative process. Based on the hypothesis that neurogenin 3 gene inhibitor, HES-1, is expressed in exocrine progenitor cells during pancreatic development ${ }^{4,6,7)}$, we proposed that immature HES-1positive exocrine cells might be identifiable in the pancreas after ANP. However, this study revealed no cells expressing HES-1 specifically and intensely.

In the present study, a pancreatic ductal-type cell thought to be a pancreatic progenitor cell was observed in human pancreas from AIP patients. This cell could be an immature cell able to differentiate into endocrine or exocrine cells during regeneration. Regenerative activities were elicited after rat AEP; however, the regeneration might progress independent of pancreatic progenitor cells. This suggests that regeneration following rat AEP (observed as disappearance of vacuoles in acinar cells) is distinct from typical regeneration. On the other hand, regeneration after both ANP in rats and human AIP is dependent on pancreatic progenitor cells. Regeneration after ANP might require dedifferentiation of pancreatic cells or presence of embryonic stem cells in the insulted pancreas. Although we could not locate pancreatic exocrine progenitor cells after acute pancreatitis, this study hinted that distinct regenerative processes ensue following different types of rat acute pancreatitis.

The present study indicated that the regenerating pancreatic endocrine and exocrine cells after human AIP might arise from ductal-type cells. The two rat models of acute pancreatitis showed differences in regenerative activity. In particular, pancreatic progenitor cells were not observed during regeneration after AEP, while progenitor cells appearing after ANP may differentiate into pancreatic endocrine or exocrine cells.

\section{Acknowledgements}

We thank Drs. Yoshitaka Kajimoto, Hideaki Kaneto, and Tetsuo Sudo for kindly providing antibodies against PDX-1, PDX-1, and HES-1, respectively. We also thank Drs. Ryoichiro Kageyama and Itaru Imayoshi for technical guidance regarding the HES-1 immunohistochemistry.

This work was supported in part by the Research Committee of Intractable Pancreatic Disease (Chairman, Dr. Makoto Otsuki), provided by the Ministry of Health, Labour, and Welfare of Japan. And it was also supported in part by a Showa University Special Grand-in-Aid for Innovative Collaborative Research Projects and a Special Research Grand-in-Aid for development of Characteristic education from the Japanese Ministry of Education, Culture, Sports, Science and Technology. 


\section{References}

1) Members of the criteria committee for autoimmune pancreatitis of the Japna Pancreas Society: Diagnostic criteria for autoimmune pancreatitis by the Japan Pancreas Society (2002). J Jpn pancreas Soc 17:585-587 (2002) (in Japanese)

2) Miyazaki S, Yamato E and Miyazaki J: Regulated expression of PDX-1 promotes in vitro differentiation of insulin-producing cells from embryonic stem cells. Diabetes $53: 1030-1037$ (2004)

3) Taniguchi $H$, Yamato $E$, Tashiro F, Ikegami H, Ogihara $T$ and Miyazaki J: $\beta$-cell neogenesis induced by adenovirus-mediated gene delivery of transcription factor PDX-1 into mouse pancreas. Gene Ther 10:15-23 (2003)

4) Jensen JN, Cameron E, Garay MVR, Starkey TW, Gianani R and Jensen J: Recapitulation of elements of embryonic development in adult mouse pancreatic regeneration. Gastroenterology $128: 728-741$ (2005)

5) Taguchi M, Yamaguchi $T$ and Otsuki M: Induction of PDX-1-positive cells in the main duct during regeneration after acute necrotizing pancreatitis in rats. $J$ Pathol $197: 638-646$ (2002)

6) Su Y, Bucbler P, Gazdbar A, Giese N, Reber HA, Heines OJ, Giese T, Bucbler MW and Friess H: Pancreatic regeneration in chronic pancreatitis requires activation of the Notch signaling pathway. $J$ Gastrointest Surg 10 : 1230-1242 (2006)

7) Rooman I, Medts ND, Baeyens L, Lardon J, Breuck SD, Heimberg H and Bouwens L: Expression of the Notch signaling pathway and effect on exocrine cell proliferation in adult rat pancreas. Am J Pathol 169: $1206^{-}$ 1214 (2006)

8) Okazaki K, Kawa S, Kamisawa T, Naruse S, Tanaka S, Nishimori I, Ohara H, Ito T, Kiriyama S, Inui K, Shimosegawa T, Yamaguchi K, Yamaguchi T, Sugiyama M and Otsuki M: Clinical diagnostic criteria of autoimmune pancreatitis: revised proposal. J Gastroenterol $41: 626-631$ (2006)

9) Slater SD, Williamson RCN and Foster CS: Proliferation of parenchymal epithelial cells enhanced in chronic pancreatitis. J Pathol $186:$ 104-108 (1998)

10) Bhave SA, Stone JS, Rubel EW and Coltrera MC: Cell cycle progression in gentamicin-damaged avian cochleas. J Neurosci 15 : 14618-4628 (1995)

11) Rasanen TL, Alhonen L, Sinervirta R, Keinanen T, Herrzig KH, Suppola S, Khomutove AR, Vepsalaonen J and Janne $\mathrm{J}$ : A polyamine analogue prevents acute pancreatitis and restores early liver regeneration in transgenic rats with activated polyamine catabolism. J Biol Chem $18: 39867-39872$ (2002)

12) Ohno N, Izawa A,Hattori $M$, Kageyama $R$ and Sudo $T$ : dlk inhibits stem cell factor-induced colony formation of murine hematopoietic progenitors: Hes-1-independent effect. Stem Cells 19:71-79 (2001)

13) Saito T, Tanaka S, Yoshida H, Imamura T, Ukegawa J, Seki T, Ikegami A, Yamamura F, Mikami T, Aoyagi Y, Niikawa $\mathrm{J}$ and Mitamura $\mathrm{K}$ : A case of autoimmune pancreatitis: responding to steroid therapy. Pancreatology $2: 550-556$ (2002)

14) Yoshida H, Tanaka S, Yamazaki T, Yukawa A, Honma T, Kitamura K, Awai T, Hanawa K, Imamura T, Ikegami $\mathbf{A}$ and Imawari $\mathbf{M}$ : An animal model and immunopathy for autoimmune pancreatitis: Elucidation of pathophysiology of the disease by utilizing aly/aly male mice. Med Frontline 66:99-108 (2007) (in Japanese)

15) Ikegami A, Yoshida H, Takahashi A, Tanaka S, Niikawa J, Imamura T, Kitamura K and Mitamura K: Involvement of $\mathrm{Ca}^{2+} /$ calmodulin-dependent protein kinase II in acceleration of pancreatic insult. Showa Univ J Med Sci $12: 149-161$ (2000)

16) Honma $T$, Yoshida H, Niikawa J, Tanaka S, Yamazaki $T$, Kitamura K, Imamura T, Ikegami A, Kawaguchi $T$ and Imawari $\mathrm{M}$ : Protease-activated receptor 2(PAR-2) in pancreatic macrophages/monocytes is involved in exacerbation of acute pancreatitis in rats. Showa Univ J Med Sci 18 : 51-64 (2006)

17) Niikawa J, Shin S, Omachi H, Ohta H, Takayama H, Kawada T, Funatomi H, Taguchi S, Hatta Y, Morohoshi T and Kanda M: Study on regeneration of pancreatic acinar cells in the rat pancreatitis induced by two doses of DL-ethionine. J Jpn Pancreas Soc 2 : 30-38 (1987) (in Japanese)

18) Niikawa J, Shin S, Omachi H, Kawada T, Takayama H, Nakano I, Funatomi H, Taguchi S and Hatta Y: Study on pancreatic degeneration and regeneration in the rat pancreatic damage induced by two doses of DLethionine. J Jpn Pancreas Soc 2 : 86-98 (1987) (in Japanese) 